\title{
Flame resistant cellulosic substrate using banana pseudostem sap
}

\author{
S. Basak*, Kartick. K. Samanta*, S. Saxena, S.K. Chattopadhyay, R. Narkar, R. Mahangade, \\ G.B. Hadge \\ Central Institute for Research on Cotton Technology (CIRCOT), Indian Council of Agricultural Research, Chemical and \\ Biochemical Division, Adenwala Road, Matunga, Mumbai 400019, India \\ "Corresponding authors: e-mail: shantanubasak@gmail.com, karticksamanta@gmail.com
}

\begin{abstract}
Flame retardancy was imparted in cellulosic cotton textile using banana pseudostem sap (BPS), an eco-friendly natural product. The extracted sap was made alkaline and applied in pre-mordanted bleached and mercerized cotton fabrics. Flame retardant properties of both the control and the treated fabrics were analysed in terms of limiting oxygen index (LOI), horizontal and vertical flammability. Fabrics treated with the non-diluted BPS were found to have good flame retardant property with LOI of 30 compared to the control fabric with LOI of 18, i.e., an increase of 1.6 times. In the vertical flammability test, the BPS treated fabric showed flame for a few seconds and then, got extinguished. In the horizontal flammability test, the treated fabric showed no flame, but was burning only with an afterglow with a propagation rate of $7.5 \mathrm{~mm} / \mathrm{min}$, which was almost 10 times lower than that noted with the control fabric. The thermal degradation and the pyrolysis of the fabric samples were studied using a thermogravimetric analysis (TGA), and the chemical composition by FTIR, SEM and EDX, besides the pure BPS being characterized by EDX and mass spectroscopy. The fabric after the treatment was found to produce stable natural khaki colour, and there was no significant degradation in mechanical strengths. Based on the results, the mechanism of imparting flame retardancy to cellulosic textile and the formation of natural colour on it using the proposed BPS treatment have been postulated.
\end{abstract}

Keywords: banana pseudostem sap, cellulose, cotton fabric, flame retardant, thermogravimetry.

\section{INTRODUCTION}

Cotton is $100 \%$ cellulosic in nature, catches flame readily and it is quite difficult to extinguish the same, resulting in serious health risk and damage to textile products (Petrilli, 2008). Significant efforts have been made from the sixteen century to improve the flame retardant property of cotton textile using various synthetic chemicals. The simple and common nondurable, fire retardant chemicals available in the market are inorganic salts, borax and boric acid mixture ${ }^{1}$, di-ammonium phosphate, urea etc ${ }^{2}$. In the last decade of $19^{\text {th }}$ century, the UK researchers also used polyurethane foam and antimony based halogen containing formulations as a back coating on cotton textile to make it fire retardant. However, antimony in combination with halogen though could impart good flame retardancy, was not very successful due to the negative environmental impact of the halogen compounds ${ }^{3}$. A phosphorous based flame retardant along with nitrogenous compound has been reported to be the most effective so far due to their synergistic effect. Consequently, for the last fifty years, flame retardants based on the composition of phosphorous, nitrogen and halogen like Tetrakis phosphonium salt and $\mathrm{N}$-alkyl phosphopropionamide derivatives are widely dominating in the market as commercial flame retardant products ${ }^{3}$. However, when such formulations are applied on cotton fabric, its tear and tensile strengths are reduced, and the fabric becomes stiff as it is applied in acidic condition. Besides, the treatment is toxic, hazardous, expensive and also, time consuming due to involvement of high quantity chemical and high temperature curing process ${ }^{4}$.

Hence, there is the need to develop more cost-effective, environmentally friendly and sustainable fire retardant chemicals which, when applied to cotton fabrics will maintain its quality to a great extent. In this direction, the researchers have tried to reduce the quantity of formaldehyde release from fire retardant fabric by using Butane tetra carboxylic acid binding formulation ${ }^{5}$. Besides, they are also working to develop halogen free phosphorous and nitrogen bonded flame retardant to create more char forming cellulosic substrate $^{6}$. Recently, a research group used nano zinc oxide and polycarboxylic acid to make environmentally friendly fire retardant cotton fabric ${ }^{7}$. However, developments of easily applicable, effective and environmental friendly and cheaper fire retardants for cellulosic textiles are still a challenge for the researchers. It may be noted that due to recent awareness about human health and hygiene, the demand of cellulosic textile finishes with natural products, such as natural dyes for colouration, enzyme for bio-polishing ${ }^{8}$, neem, aloe vera and banana peel extract for antimicrobial finishing is getting attention in research and development, ${ }^{\mathbf{9}}$. Very few researches have been reported regarding the fire retardancy of cellulosic fabric using bio-macromolecules. Very recently, a group of researchers has reported to apply DNA from herring sperm and salmon fishes on the cotton fabric to make it thermally stable ${ }^{\mathbf{1 1}-13}$. They have opined that since DNA contains phosphate, carbonaceous deoxyribose units, polysaccharide dehydrate and some essential amino acids that helped in carbonaceous char formation and ammonia release, thus making the cellulosic cotton textile thermally stable ${ }^{11}$. They have also attempted to make fire retardant cotton fabric with whey proteins, casein and hydrophobins due to their phosphate, disulphide and protein content that can influence their pyrolysis by early char formation ${ }^{12},{ }^{13}$. However, till date application of plant extract (bio-molecules) for flame retardant finishing of any textile and/or polymeric material has not been reported to the best of our knowledge. As some of the plants are known to contain phosphorous and 
other minerals, they can be suitably utilized to impart flame retardancy to cellulosic and non-cellulosic textiles.

In the present research, an attempt has been made to provide the flame retardancy to cellulosic cotton textiles by using banana pseudostem sap (BPS), a plant extract, as it contains phosphorous, nitrogen, chlorine and other metallic constituents ${ }^{\mathbf{1 4}}$. A group of researchers has also shown that the BPS contains magnesium nitrate and potassium nitrate ${ }^{\mathbf{1 5}}$. More recently, researchers have reported that the potassium chloride, sodium chloride and metal phosphate are the major components of the salts extracted from BPS ${ }^{\mathbf{1 6}}$. Further, the BPS is abundantly available in India and is normally considered as a waste material. In the present study, the effect of the BPS on the cotton textile with regard to assessment of flammability, wash durability and mechanical strengths have been extensively investigated and characterised by thermogravimetry, SEM, EDX and TOF-SIMS.

\section{MATERIAL AND METHODS}

\section{Material and BPS application}

A $0.2 \mathrm{Kg} / \mathrm{m}^{2}$ (areal density) plain woven bleached cotton fabric of 12 EPC (ends/cm) and 16 PPC (picks/ $\mathrm{cm}$ ) was used for flame retardant finishing by the BPS. The bleached cotton fabric was first mordanted with $5 \%$ tannic acid and $10 \%$ alum and then, impregnated with different concentrations of the BPS such as, non-diluted (1: 0$)$ and diluted (1: 1 and 1: 2), keeping material to BPS ratio at 1: 10 . The fabric was dipped in each application for $30 \mathrm{~min}$ maintaining an alkaline $\mathrm{pH}$ using soda ash. The treated fabric samples were dried at $110^{\circ} \mathrm{C}$ for $5 \mathrm{~min}$.

\section{Determination of add-on \%}

The fabric samples were conditioned at $65 \% \mathrm{RH}$ and $27^{\circ} \mathrm{C}$ for $48 \mathrm{~h}$. After the application of the BPS, the percent add-on, i.e., the increase in the sample weight relative to the original weight was determined by the gravimetric method as follows:

Add-on $(\%)=\left[\left(\mathrm{M}_{2}-\mathrm{M}_{1)} / \mathrm{M}_{1}\right] \times 100\right.$

where, $M_{1}$ and $M_{2}$ are the oven dried weights of the control (before mordanting) and the BPS treated samples respectively. The reported results are average of 5 readings.

\section{Thermal characterization}

\section{Flammability assessment}

Before the flammability testing, all the samples were conditioned in a standard atmosphere of $65 \% \mathrm{RH}$ for $24 \mathrm{hrs}$, so that they are identically acclimatised. The burning behaviour of the control and the treated samples were evaluated as per the standard methods. For determination of Limiting Oxygen Index (LOI), an ignition time of $30 \mathrm{~s}$ was maintained as per the Indian standard IS 13501. In horizontal flammability tests, the flame-time and the propagation rate was measured as per FMVSS302N standard. Here, the fabric sample was ignited with a flame of $38 \mathrm{~mm}$ height for $12 \mathrm{~s}$. In vertical flammability tests, the different parameters were measured as per the IS 1871 method A. Here also, the fabric sample was ignited with a flame for $10 \mathrm{~s}$. The maximum temperature produced during the burning of the sample was measured using an IR thermometer (Fisher Scientific, Model No. 15077968 FB61354 225PE) in non-contact mode.

\section{Thermogravimetry (TGA) analysis}

The thermogravimetry measures the gradual weight loss of a sample with respect to time at a constant heating rate. It also indicates the effect of any flame retardant chemical on the pyrolysis of the polymer substrate ${ }^{\mathbf{1 8}}$. The TGA curves of the control and the treated fabrics were drawn on a Thermo Gravimetric Analyser (METTLER TOLEDO TG-50/ MT5) in a nitrogen atmosphere at $2 \mathrm{ml} / \mathrm{min}$ flow rate and at $10^{\circ} \mathrm{C} / \mathrm{min}$ heating rate. The TGA curves of the control and the BPS treated fabrics were also taken in air atmosphere under similar flow and heating conditions to understand the thermo-oxidative decomposition.

\section{FTIR analysis}

The FTIR analyses of the samples were carried out in Shimadzu IR Prestige 21 analyser over the wavelength of 500 to $4500 \mathrm{~cm}^{-1}$ using the $\mathrm{KBr}$ disc sample preparation method and an ATR transmittance mode with DLaTGS detector for 49 scans and 4 resolutions.

\section{SEM, EDX and ToF-SIMS analysis}

The Surface of both the control and the BPS treated samples were analysed using a scanning electron microscope, Philips XL-30. The samples were coated with a thin layer of conducting material (Gold/ palladium) by using a sputter coater and examined under the SEM with an accelerating voltage of $12 \mathrm{KV}$. The EDX analysis of the samples was carried out in a Field Emission Gun Scanning Electron Microscope (FEG-SEM) to determine the quantity of the elements present on the surface, and was expressed both in atomic and weight percent. Time-of-Flight Secondary Ion Mass Spectrometry (ToF-SIMS) was carried out in LMIG, cesium and gas ion guns.

\section{Wash durability of finish}

The flame retardant activity of the finished samples was evaluated after washing the samples as per the ISO 1 method. According to this method, the treated fabrics were washed in a laundrometer using a standard detergent with concentration of $5 \mathrm{~g} / 1$ at $40^{\circ} \mathrm{C}$ for $30 \mathrm{~min}$. The fabric was then rinsed in fresh water for $5 \mathrm{~min}$, followed by drying at $100^{\circ} \mathrm{C}$ for another $5 \mathrm{~min}$. The samples were then conditioned in a desiccator for $24 \mathrm{~h}$ in a standard atmosphere.

\section{Colour parameters}

It was observed that after application of the BPS in the cotton textile, its colour changed from white to khaki and the colour parameters such as $\mathrm{K} / \mathrm{S}, \mathrm{L}$, a and b were measured using a Perkin-Elmer double beam spectrophotometer, Lambda (35 model) equipped with an integrating sphere. The colour depth of the BPS treated fabrics was determined in terms of $\mathrm{K} / \mathrm{S}$ from the reflectance data using the Kubelka-Munk equation as follows:

$\mathrm{K} / \mathrm{S}=(1-\mathrm{R})^{2} / 2 \mathrm{R}$ 
where, $\mathrm{K}$ is the absorption coefficient, $\mathrm{S}$ the scattering coefficient and $\mathrm{R}$ is the reflectance of the treated fabric at the wavelength of maximum absorption. The K/S was determined at $213 \mathrm{~nm}\left(\lambda_{\max }\right)$ of the respective dye. Other colour parameters such as $\mathrm{L}^{*}$ (lightness-darkness), $\mathrm{a}^{*}$ (red-green) and $\mathrm{b}^{*}$ (blue-yellow component) were measured using the Win lab software, delta-E 1976.

\section{Mechanical strengths}

The tensile and the tear strength, the two most important properties of textiles were evaluated using an Instron tensile tester as per ASTM D5035 and ASTM D101 standard, respectively. The control and the treated samples were compared to study the effect of the BPS on the mechanical properties of the samples.

\section{RESULTS AND DISCUSSION}

\section{LOI, horizontal and vertical flammability}

The results of the flammability tests are presented in Table 1. The LOI, a measure of the flammability of a sample is defined as the minimum quantity of oxygen in the oxygen/nitrogen mixture required to support the combustion. Textiles having LOI values of 21 or below, ignite easily and burn rapidly in the open atmosphere. However, the sample with the LOI value of above 21, ignite but burn slowly, and with LOI value equal to or more than 26, its combustion becomes slower in $\operatorname{air}^{17,18}$. The LOI values of the control, the mordanted and the BPS treated cotton fabrics are given in Table 1 .

As indicated above, cotton is pure cellulosic in nature, catches flame readily depicting an LOI value of 18 . It remain the same in the mordanted (with tannic acid and alum) sample. However, after application of the BPS in the mordanted cotton samples, the LOI value was found to increase significantly. When the mordanted fabrics were treated with 1: 2 BPS solution (BPS: water), the LOI value was found to increase to 26 , which is almost
1.4 times higher than that obtained with the control sample. When the concentration of the BPS increased to 1: 0 , the add-on percentages increased from 2 to 4.5 , resulting in an increase in the LOI linearly from 26 to 30. It may be noted that in all the BPS treated samples, as the LOI value has increased significantly, the samples do not ignite. In the vertical flammability measurement, it was observed that the control sample ignite readily, and burnt entirely with flame within $60 \mathrm{~s}$. However, the BPS treated sample (1:2) showed the presence of flame only for $10 \mathrm{~s}$ (partial burning) followed by combustion with afterglow in $500 \mathrm{~s}$, and thus, recording a total burning time of $510 \mathrm{~s}$.

Figure 1 represents the vertical burning behaviour of the control and the BPS treated (1:0) sample at different interval of time. It is seen that in the BPS treated (1:2) sample, the total burning time could be increased by 8.5 folds compared to that noted with the control sample. With the increase in concentration of BPS (1: 0), consequently the add-on percentage, the burning with flame time could be reduced further to $4 \mathrm{~s}$ from $10 \mathrm{~s}$, and the burning with the afterglow rate from 29.4 to $16.6 \mathrm{~mm} /$ min. Thus, the afterglow time recorded for the 1: 0 BPS treated sample was $900 \mathrm{~s}$. It may be noted that as far as the flammability is concerned, the combustion with afterglow may not so serious compared to the combustion with flame, where the maximum temperature was found to be $350^{\circ} \mathrm{C}$. The same was $395-400^{\circ} \mathrm{C}$ for the control sample. It is very interesting to note that the maximum temperature measured during the burning of the BPS treated samples with afterglow decreased gradually with the burning time, initially $320^{\circ} \mathrm{C}$, followed by 280,250 and finally $120^{\circ} \mathrm{C}$ at an interval of $60 \mathrm{~s}$. It will be very much helpful in real life situation as the wearer of the clothing will get a longer escape time (900 s) to escape from fire zone or to extinguish the flame. In contrast, the user will be getting hardly any time ( $60 \mathrm{~s}$ only) to escape from fire hazards with an environment tempe-

Table 1. Flammability parameters of control, mordanted and BPS treated (pre-mordanted) cotton fabrics

\begin{tabular}{|c|c|c|c|c|c|}
\hline \multirow{3}{*}{ Flammability parameters } & \multirow{3}{*}{ Control } & \multirow{3}{*}{ Mordanted } & \multicolumn{3}{|c|}{ BPS treated cellulosic cotton fabric } \\
\hline & & & \multicolumn{3}{|c|}{ BPS: Water concentration } \\
\hline & & & $1: 2$ & $1: 1$ & $1: 0$ \\
\hline Add on [\%] & - & & 2 & 3.5 & 4.5 \\
\hline LOI & 18 & 18 & 26 & 28 & 30 \\
\hline \multicolumn{6}{|c|}{ Horizontal flammability } \\
\hline $\begin{array}{l}\text { Warp way burn rate } \\
{[\mathrm{mm} / \mathrm{min}]}\end{array}$ & 75 & 75 & 14 & 8 & 7.5 \\
\hline \multicolumn{6}{|c|}{ Vertical flammability } \\
\hline $\begin{array}{l}\text { Occurring of flashing over } \\
\text { the surface }\end{array}$ & Yes & Yes & No & No & No \\
\hline $\begin{array}{l}\text { Burning with flame time } \\
\text { [s] }\end{array}$ & 60 & 60 & 10 & 7 & 4 \\
\hline $\begin{array}{l}\text { Burning with afterglow time } \\
\text { [s] after the flame } \\
\text { extinguished }\end{array}$ & $\begin{array}{c}0 \\
\text { (As completely } \\
\text { burnt with flame) }\end{array}$ & $\begin{array}{c}0 \\
\text { (As completely } \\
\text { burnt with flame) }\end{array}$ & 500 & 680 & 900 \\
\hline $\begin{array}{l}\text { *Total burning time [s] } \\
\text { (flame time+ afterglow } \\
\text { time) }\end{array}$ & $60+0$ & $60+0$ & $10+500$ & $7+680$ & $4+900$ \\
\hline Char length $[\mathrm{mm}]$ & Nil & Nil & Nil & Nil & Nil \\
\hline $\begin{array}{l}\text { Observed burning rate } \\
\text { [mm/min] }\end{array}$ & 250 & 250 & 29.4 & 21.8 & 16.6 \\
\hline $\begin{array}{l}\text { State of the fabric in } \\
\text { contact of flame }\end{array}$ & $\begin{array}{l}\text { Completely Burnt } \\
\text { with flame }\end{array}$ & $\begin{array}{l}\text { Completely Burnt } \\
\text { with flame }\end{array}$ & $\begin{array}{l}\text { Burnt initially with } \\
\text { flame followed by } \\
\text { afterglow }\end{array}$ & $\begin{array}{l}\text { Burnt initially with } \\
\text { flame followed by } \\
\text { afterglow }\end{array}$ & $\begin{array}{l}\text { Burnt initially with } \\
\text { flame followed by } \\
\text { afterglow }\end{array}$ \\
\hline
\end{tabular}

${ }^{*}$ Total burning time of the fabric = Burning with flame time + burning with afterglow time (after the flame extinguished). 

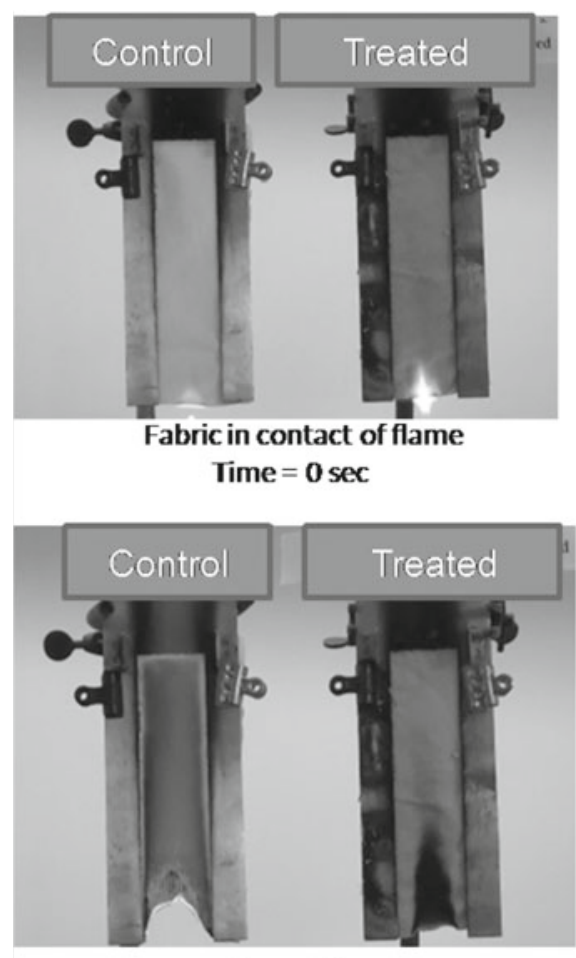

Time $=\mathbf{2 0} \mathbf{s e c}$

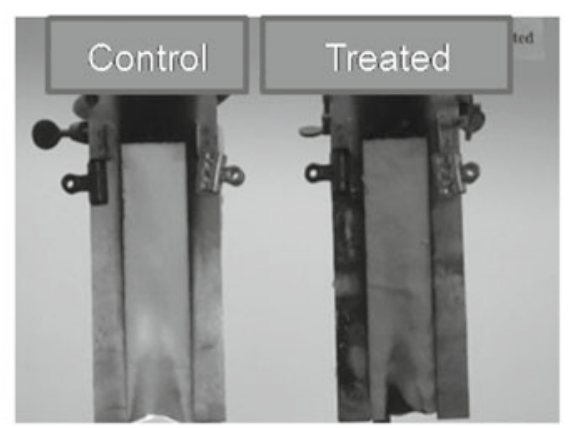

After removal of flame

Time $=10$ sec

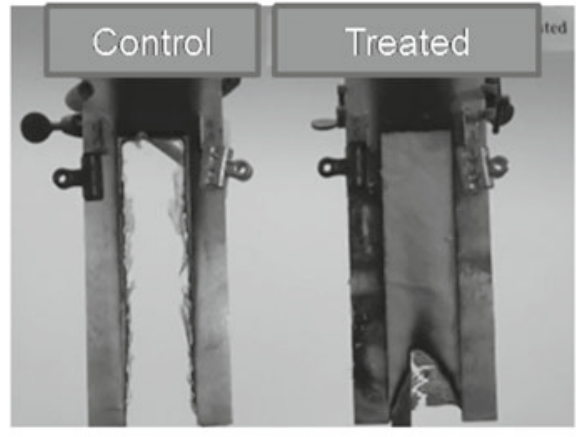

Time $=60 \mathrm{sec}$

Figure 1. Comparison in burning behaviour of control and BPS treated (1: 0) cotton fabrics at different time interval

rature of $\sim 400^{\circ} \mathrm{C}$. However, the escape time in a real fire scenario is not the same as the combustion time in a specific test, despite it can be correlated. In any flame retardant finishing of textile material, it will be beneficial if the flame ignited on the flame-retardant-treated fabric is extinguished right after the removal of the ignition source. An afterglow might be present, however, in the BPS treated cotton textile, the glow temperature $\left(320-120^{\circ} \mathrm{C}\right)$ is much lower than the control sample. In the treated fabrics, as the LOI value increased with the percentage add-on of the pseudostem sap, the afterglow time was found to increase significantly from $0 \mathrm{~s}$ (control) to $500 \mathrm{~s}, 680 \mathrm{~s}$ and $900 \mathrm{~s}$ for the 1: 2, 1: 1 and 1: 0 BPS treated samples, respectively. The BPS treated samples were mostly burnt with afterglow with the burning rate reduced significantly from $250 \mathrm{~mm} /$ min for the control sample to $16.6 \mathrm{~mm} / \mathrm{min}$ for the $1: 0$ BPS treated sample. Similar trends were also observed in the horizontal flammability measurement, where the burning rate in 1: 0 BPS treated sample reduced from $75 \mathrm{~mm} / \mathrm{min}$ to $7.5 \mathrm{~mm} / \mathrm{min}$, which is 10 times lower than the control sample. In the control as well in the BPS treated samples, no char length was observed, as both the samples burnt completely.

\section{Thermogravimetry (TGA)}

Figure 2 shows the TGA curves of the control (A), mordanted (B) and the BPS treated cotton fabrics at two different concentrations of BPS $(\mathrm{C} \& \mathrm{D})$ in $\mathrm{N}_{2}$ atmosphere at a heating rate of $10^{\circ} \mathrm{C} / \mathrm{min}$. The TGA curves of the control (A) and the mordanted (B) samples evidenced three stages of progression. In the initial stage at temperature below $300^{\circ} \mathrm{C}$, the little mass loss occurred mainly due to the removal of bound and unbound absorbed moisture from the cellulose polymer ${ }^{19}$. However, the main thermal decomposition occurred in the temperature range of $300-360^{\circ} \mathrm{C}$, where the mass of the sample sharply decreased at around $340^{\circ} \mathrm{C}$. This has happened mainly due to the pyrolysis of cellulose $\mathrm{e}^{\mathbf{2 0}}$.

Above the temperature of $360^{\circ} \mathrm{C}$, both dehydration and char formation occurred. It is presumed that in dehydration, the non-oxidizable water and $\mathrm{CO}_{2}$ might have been released ${ }^{21}$. An identical trend in mass loss, i.e., degradation was also observed in the only mordanted sample. It could be seen that the samples A \& B lost approximately $98 \%$ of its mass below $500^{\circ} \mathrm{C}$. A similar phenomenon was also observed in vertical flammability measurements, where the control and the mordanted fabric burn completely with a maximum temperature of $400^{\circ} \mathrm{C}$. Further, the burning rate was as high as $250 \mathrm{~mm} /$ min as noted in the vertical flammability test. Unlike the control and the mordanted fabrics (A \& B), the BPS treated cotton fabrics (C \& D) started losing more mass at the initial stage below $200^{\circ} \mathrm{C}$. It might be due to the removal of more amount of bound and unbound moisture from the BPS treated fabric. Here, the main thermal decomposition also occurred earlier, i.e., from $250^{\circ} \mathrm{C}$, which is $50^{\circ} \mathrm{C}$ lower compared to the control sample. Also the temperature, where the main mass loss happened shifted from $340^{\circ} \mathrm{C}$ to $325^{\circ} \mathrm{C}$ for the control to the 1: $1 \mathrm{BPS}$ treated and to $315^{\circ} \mathrm{C}$ for the 1: 0 treated samples, respectively. This might be due to the presence of the BPS that had reduced the thermal decomposition and the dehydration temperature of cellulose. The BPS also had an effect on the char formation. It has increased the char formation and produced non-oxidisable gases such as $\mathrm{CO}_{2}$ and $\mathrm{H}_{2} \mathrm{O}$, while reducing the production of flammable volatile gases. As a result, the BPS treated samples showed more LOI value and lower rate of burning. The char residue at $500^{\circ} \mathrm{C}$ increased from $1 \%$ to $30 \%$ in the samples $\mathrm{A}$ to $\mathrm{D}$.

The TGA analysis was also performed in air to understand the thermo-oxidative decomposition of the control 

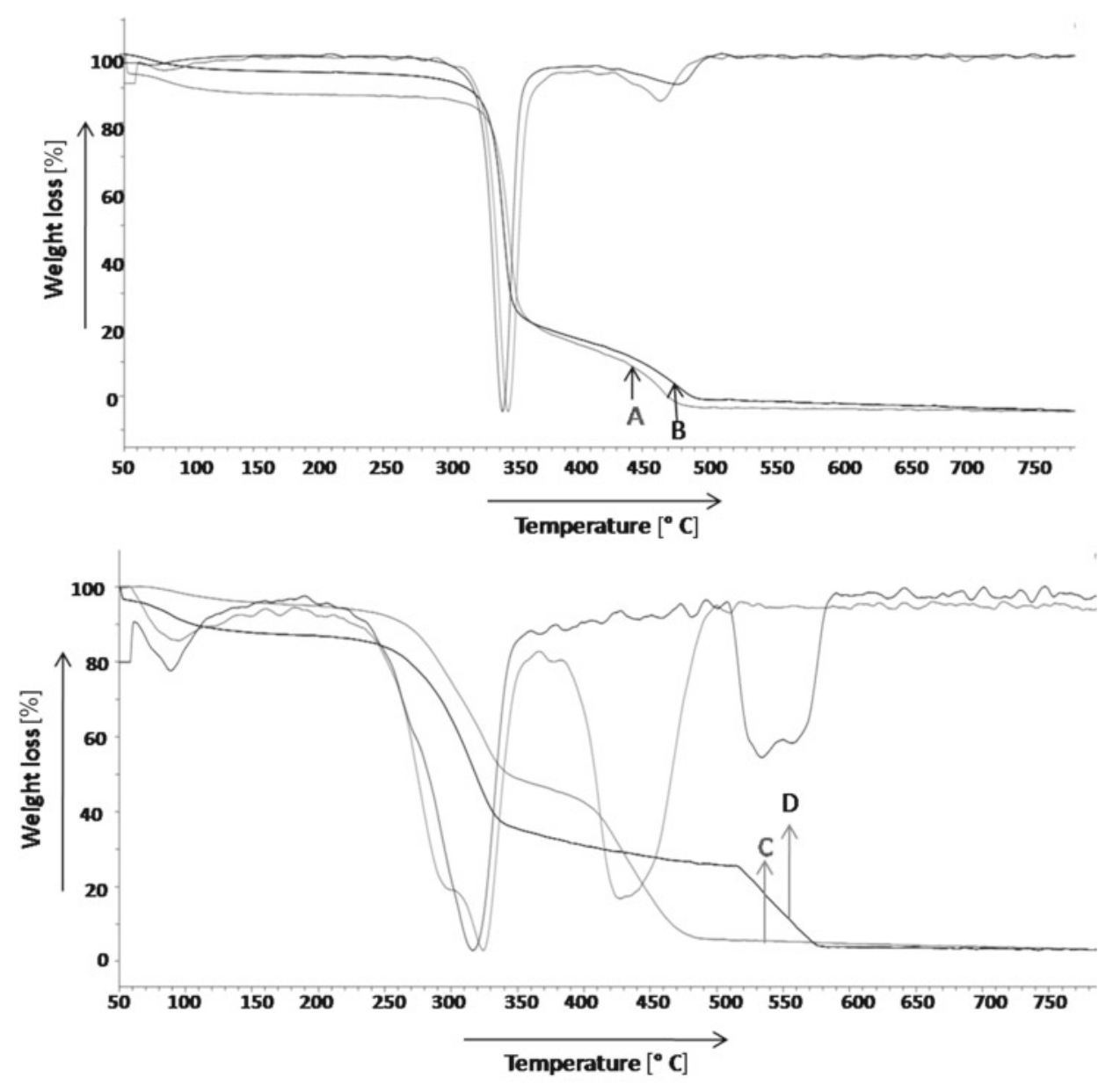

Figure 2. TGA curves of the Control (A), Mordanted (B), 1: 1 BPS treated (C) and 1: 0 BPS treated (D) cotton fabrics

and the BPS treated fabric. From the TGA curve A (Fig. 3), it was observed that for the control sample the thermo-oxidative decomposition started at $330^{\circ} \mathrm{C}$ (with decomposition peak at $345^{\circ} \mathrm{C}$ ) and lost $80 \%$ of the mass at $350^{\circ} \mathrm{C}$, whereas for the BPS treated fabric (curve B), the pyrolysis started from $200^{\circ} \mathrm{C}$ (with decomposition peak at $300^{\circ} \mathrm{C}$ ) and lost only $60 \%$ of the mass by the time the temperature reaches to $350^{\circ} \mathrm{C}$. It means that like in the $\mathrm{N}_{2}$ atmosphere, here also the BPS treatment has influenced the pyrolysis temperature of the treated fabric and accelerated the dehydration process with the generation of more amount of carbonaceous char mass. The same can also be verified from the SEM pictures of the residual mass of the BPS treated fabric as presented in Figure 8 of this paper.

\section{FTIR analysis}

Figure 4 shows the FTIR spectra of the various samples. It can clearly be observed that there is no significant difference between the curves $\mathrm{A}$ and $\mathrm{B}$. The curve $\mathrm{C}$ for the only banana pseudostem sap (BPS) showed a wide band from $3600 \mathrm{~cm}^{-1}$ to $2600 \mathrm{~cm}^{-1}$ confirming the presence of water. The observed peaks between $800 \mathrm{~cm}^{-1}$ to $1300 \mathrm{~cm}^{-1}$ wavelength were mainly due to the presence of inorganic salts in the BPS ${ }^{22}$. The FTIR absorption bands observed at $1000-1100 \mathrm{~cm}^{-1}$ might be assigned to the phosphate group ${ }^{23}$. The small peaks observed at $1176 \mathrm{~cm}^{-1}$ and $873 \mathrm{~cm}^{-1}$ might be due to the presence of magnesium chloride and potassium chloride salt respectively ${ }^{24}$. Similarly, the peak observed at $1000 \mathrm{~cm}^{-1}$ was due to the presence of sodium phosphate ${ }^{25}$. However, it is not possible to recognise specific salt compounds by the FTIR absorption only. These types of elements in the inorganic salts have also been detected in the EDX analysis of the BPS and the treated fabric as discussed in the following section. Besides, mass spectroscopy of the only BPS has also confirmed the presence of different metals and ions in the BPS as discussed in Table 3.

\section{SEM and EDX analysis}

The SEM images of the control and the BPS treated (1: 0$)$ cotton fabrics are shown in Figure 5 . It can be seen [Fig. 5 (A)], that the control sample was clean and without any deposition. However, after the BPS treatment (1: 0), the coating of BPS could easily be visible as shown in Figure 5 (B). The BPS was found uniformly distributed over the entire surface of the fabric. However, some part of it got removed after washing as shown in Figure $5(\mathrm{C})$. The energy dispersive X-ray (EDX) analysis of the control and the BPS treated fabric is presented in Figure 6 and the data are reported in Table 2. As expected, the control sample showed only the presence of carbon and oxygen atoms as the technique used can not detect hydrogen atom. However, in the BPS treated sample, several atomic peaks are easily visible (Figure $6 \mathrm{~B})$. These are corresponding to magnesium, chlorine, potassium, sodium, silicon, phosphorous, aluminium and calcium. It was also observed from Figure 6 (C) that the same metals and ions are also present in the pure BPS with larger weight and atomic percentage. Besides, in the BPS treated cotton fabric, the weight and atomic percentage of magnesium is more followed by sodium, chlorine 

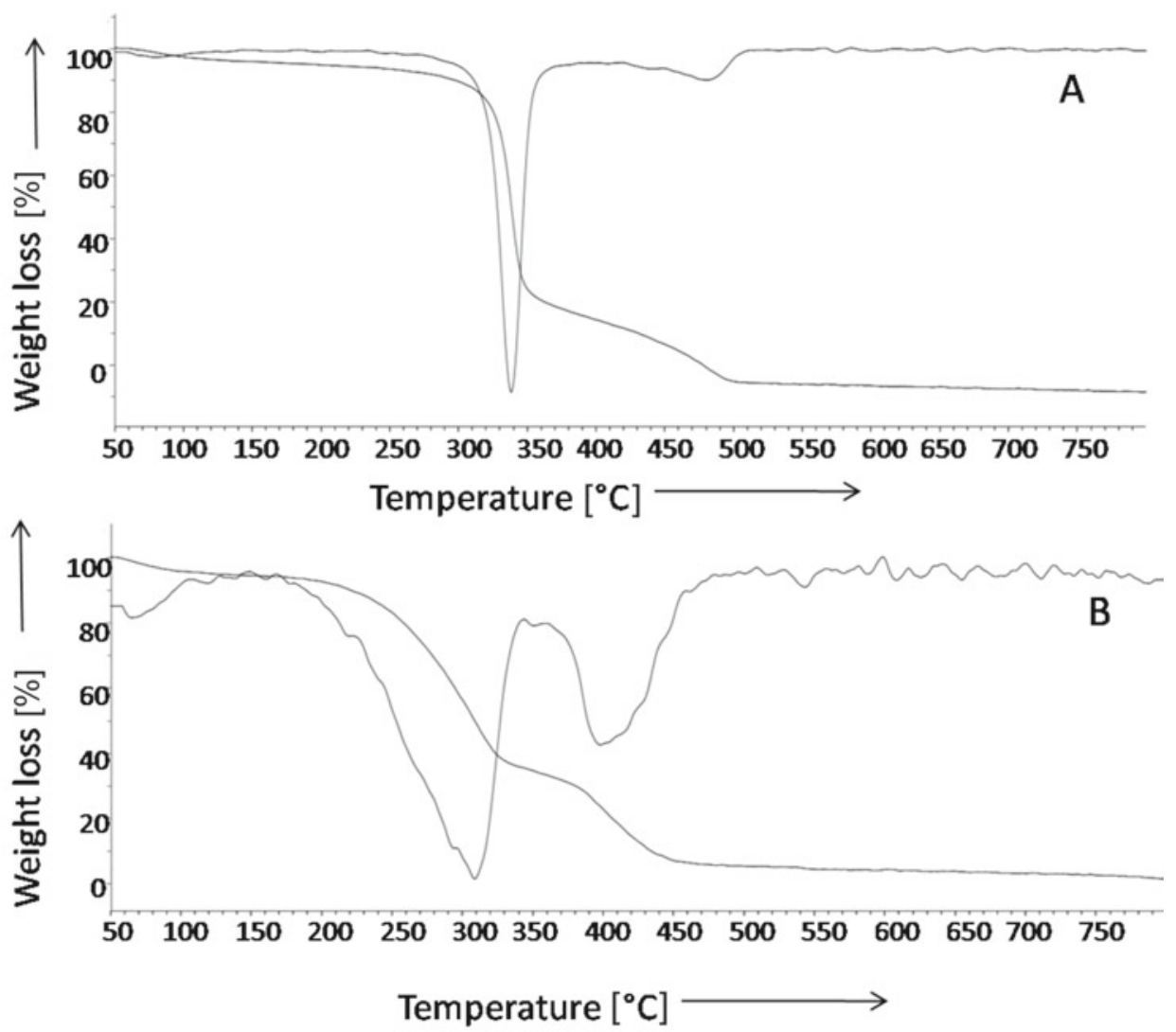

Figure 3. TGA curves of Control (A) and 1: 0 BPS treated (B) cotton fabrics

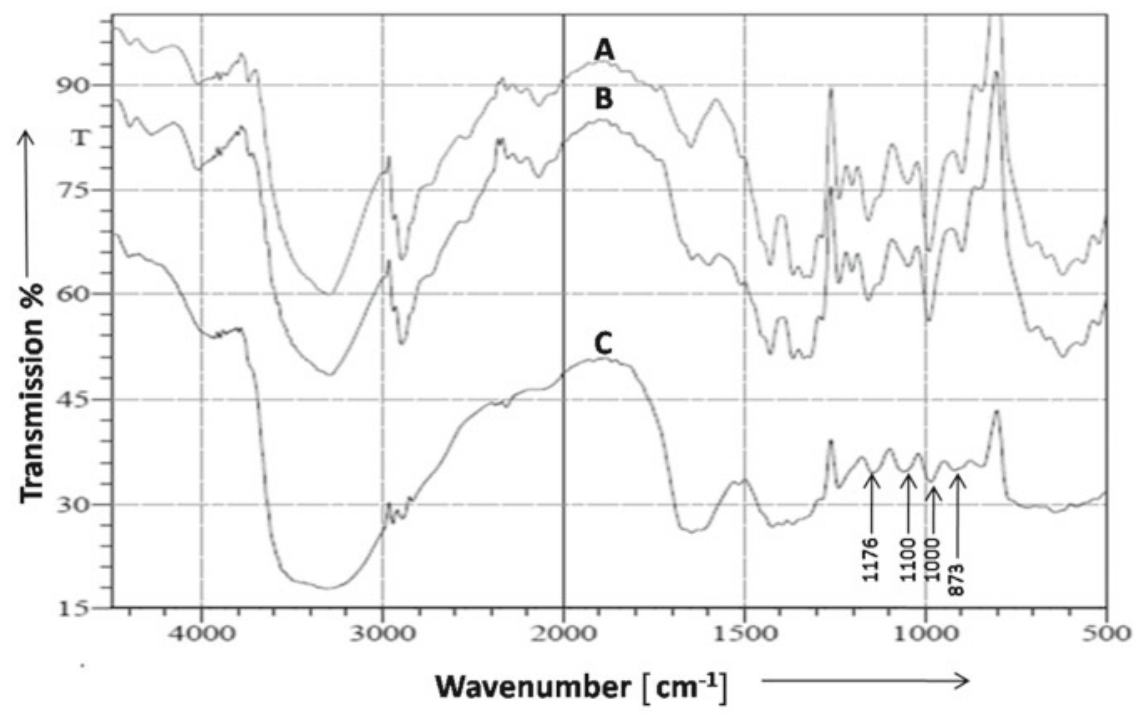

Figure 4. FTIR analysis of control fabric (A), BPS treated (1: 0) fabric (B) and dried BPS (C)

and potassium compared to the other atoms (Table 2). It is seen that carbon weight percentage is significantly lower by $(14.6 \%)$ in the BPS treated sample compared to the control sample, but oxygen percentage remains more or less the same (Table 2). Except potassium and aluminium, the elements present in the pure BPS as well BPS treated sample are in the form of either metal chloride or metal phosphate. Aluminium is being detected mainly due to the presence of mordant [Alum: $\mathrm{Al}_{2}\left(\mathrm{SO}_{4}\right)_{3}$, $\mathrm{K}_{2} \mathrm{SO}_{4}, 24 \mathrm{H}_{2} \mathrm{O}$ ]. Similarly, the presence of potassium is partially due to the mordant as well as the BPS.

\section{Surface ion mass spectroscopy (TOF-SIMS) analysis}

The negative TOF-SIMS of BPS showed the presence of $\mathrm{H}, \mathrm{C}, \mathrm{N}, \mathrm{O}, \mathrm{OH}^{-}, \mathrm{F}^{-}, \mathrm{Cl}^{-}, \mathrm{PO}_{2}^{-}, \mathrm{PO}_{3}^{-}, \mathrm{KCl}^{-}, \mathrm{KF}^{-}, \mathrm{Cl}_{2}$ etc., and the positive TOF-SIMS showed the presence of $\mathrm{Mg}^{+}, \mathrm{K}^{+}, \mathrm{Mn}^{+}, \mathrm{Fe}$ ions (Fig. 7 and Table 3). Therefore, the better flame retardancy of the BPS treated cellulosic cotton fabric might be attributed to the presence of free metal ions in the BPS. In addition to this, the presence of salts like potassium chloride, potassium fluoride, calcium chloride, phosphate, phosphite etc. are also assisting to provide better fire retardancy of the BPS treated fabric. Thus, the mass spectroscopy results of the BPS are also supporting the conclusions drawn from the FTIR and 

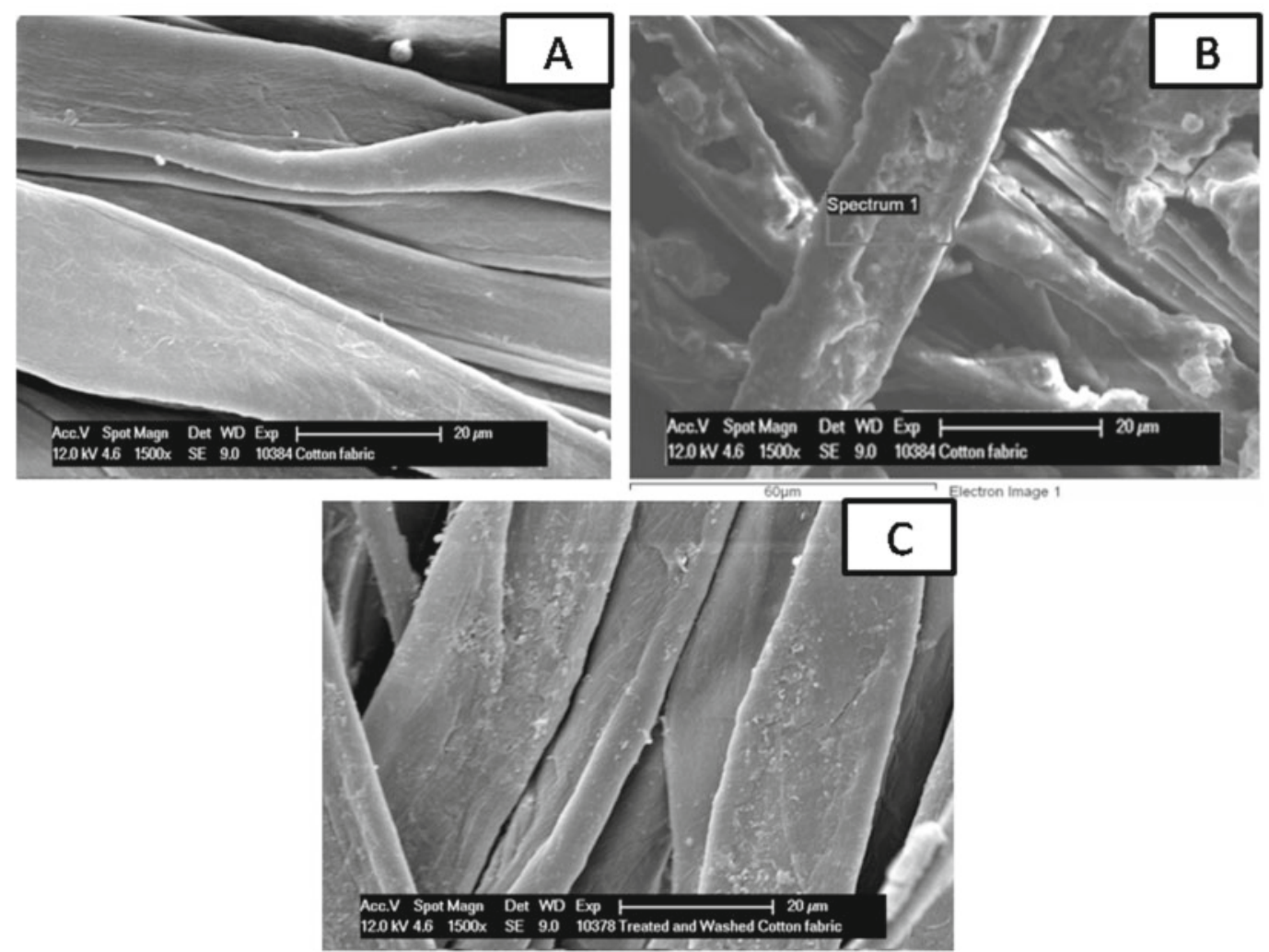

Figure 5. SEM images of Control fabric (A), BPS treated (1: 0) fabric (B), and BPS treated washed fabric (C)
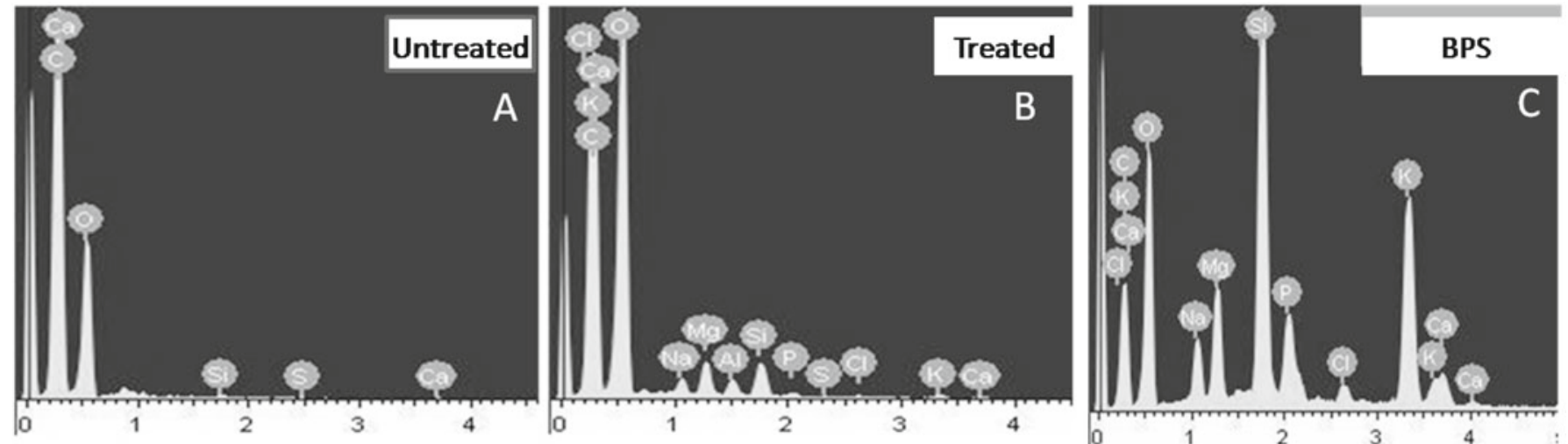

Figure 6. EDX images of untreated control (A), BPS treated (1:0) cotton fabrics (B) and BPS (C)

Table 2. Atomic and weight percentage of control and BPS treated (1:0) cotton fabric, and BPS only

\begin{tabular}{|l|c|c|c|c|c|c|}
\hline \multirow{2}{*}{ Elements } & \multicolumn{2}{|c|}{ Control } & \multicolumn{2}{c|}{ BPS treated (1:0) } & \multicolumn{2}{c|}{ BPS only } \\
\cline { 2 - 7 } & Weight [\%] & Atomic [\%] & Weight [\%] & Atomic [\%] & Weight [\%] & Atomic [\%] \\
\hline $\mathrm{C}$ & 46.1 & 53.2 & 31.5 & 40.2 & 15.3 & 24.3 \\
\hline $\mathrm{O}$ & 53.9 & 46.8 & 54.2 & 51.8 & 39.2 & 47.4 \\
\hline $\mathrm{Na}$ & 0 & 0 & 2.7 & 1.8 & 2.7 & 2.3 \\
\hline $\mathrm{Mg}$ & 0 & 0 & 5.8 & 3.7 & 5.4 & 0 \\
\hline $\mathrm{Al}$ & 0 & 0 & 0.2 & 0.1 & 0.4 & 0 \\
\hline $\mathrm{Si}$ & 0 & 0 & 0.8 & 0.4 & 15.1 & 10.4 \\
\hline $\mathrm{P}$ & 0 & 0 & 0.7 & 0.4 & 3.4 & 2.1 \\
\hline $\mathrm{Cl}$ & 0 & 0 & 1.9 & 0.8 & 2.2 & 16.2 \\
\hline $\mathrm{K}$ & 0 & 0 & 1.7 & 0.6 & 2.7 & 8.0 \\
\hline $\mathrm{Ca}$ & 0 & 0 & 0.4 & 0.2 & 2.7 & 1.3 \\
\hline $\mathrm{S}$ & 0.18 & 0.08 & 0.09 & 0.04 & 0 & 0 \\
\hline
\end{tabular}

the EDX analyses. As far as the GC-MS analysis of the BPS is concerned, it has been reported that magnesium nitrate and potassium nitrate are the two major active compounds present in $\mathrm{it}^{15}$.

\section{SEM of residual mass}

The SEM analysis was performed on the residues of the treated fabrics obtained after the flammability tests.
It showed an intact char structure of the closed cells containing many small pockets of gases. It was found that the BPS works as an additive intumescent flame retardant, which when heated, swells and forms a protective thick honeycomb like coating on the underlying heated polymeric substrate, thereby preventing the flow of volatile liquids or vapours into the flame. The coating protects the remaining polymer from thermal decompo- 
Table 3. Mass spectroscopy peaks and their quantification

\begin{tabular}{|l|c|c|c|c|}
\hline Serial No & Different molecules & Molecular formula & Mass/charge (M/Z) ratio & Intensity/ Count \\
\hline 1 & Hydrogen & $\mathrm{H}$ & 1 & $7.0 \mathrm{E}+6$ \\
\hline 2 & Carbon & $\mathrm{C}$ & 12,13 & $1.0 \mathrm{E}+6$ \\
\hline 3 & Nitrogen & $\mathrm{N}$ & 14 & $3.0 \mathrm{E}+6$ \\
\hline 4 & Oxygen & $\mathrm{O}$ & 17 & $3.0 \mathrm{E}+6$ \\
\hline 5 & Hydroxyl & $\mathrm{OH}^{-}$ & 19 & $2.0 \mathrm{E}+6$ \\
\hline 6 & Fluorine & $\mathrm{F}^{-}$ & 35,37 & $5.0 \mathrm{E}+5$ \\
\hline 7 & Chlorine & $\mathrm{Cl}^{-}$ & $70,74,72$ & $3.5 \mathrm{E}+6$ \\
\hline 8 & Chloride & $\mathrm{Cl}_{2}$ & 62,63 & 3000 \\
\hline 8 & Phosphate & $\mathrm{PO}_{2}^{-}$ & 79 & 3000 \\
\hline 9 & Phosphite & $\mathrm{PO}_{3}^{-}$ & $74,76,78$ & 2000 \\
\hline 10 & Polassium chloride & $\mathrm{KCl}^{+}$ & 40,41 & 2000 \\
\hline 11 & Potassium & $\mathrm{Mg}^{+}$ & $24,25,26$ & $5.0 \mathrm{E}+6$ \\
\hline 12 & Magnesium & $\mathrm{Al}^{+}$ & 27 & $1.0 \mathrm{E}+6$ \\
\hline 13 & Aluminium & $\mathrm{Ca}^{+}$ & 43 & $1.0 \mathrm{E}+6$ \\
\hline 14 & Calcium & & & $3.0 \mathrm{E}+5$ \\
\hline
\end{tabular}

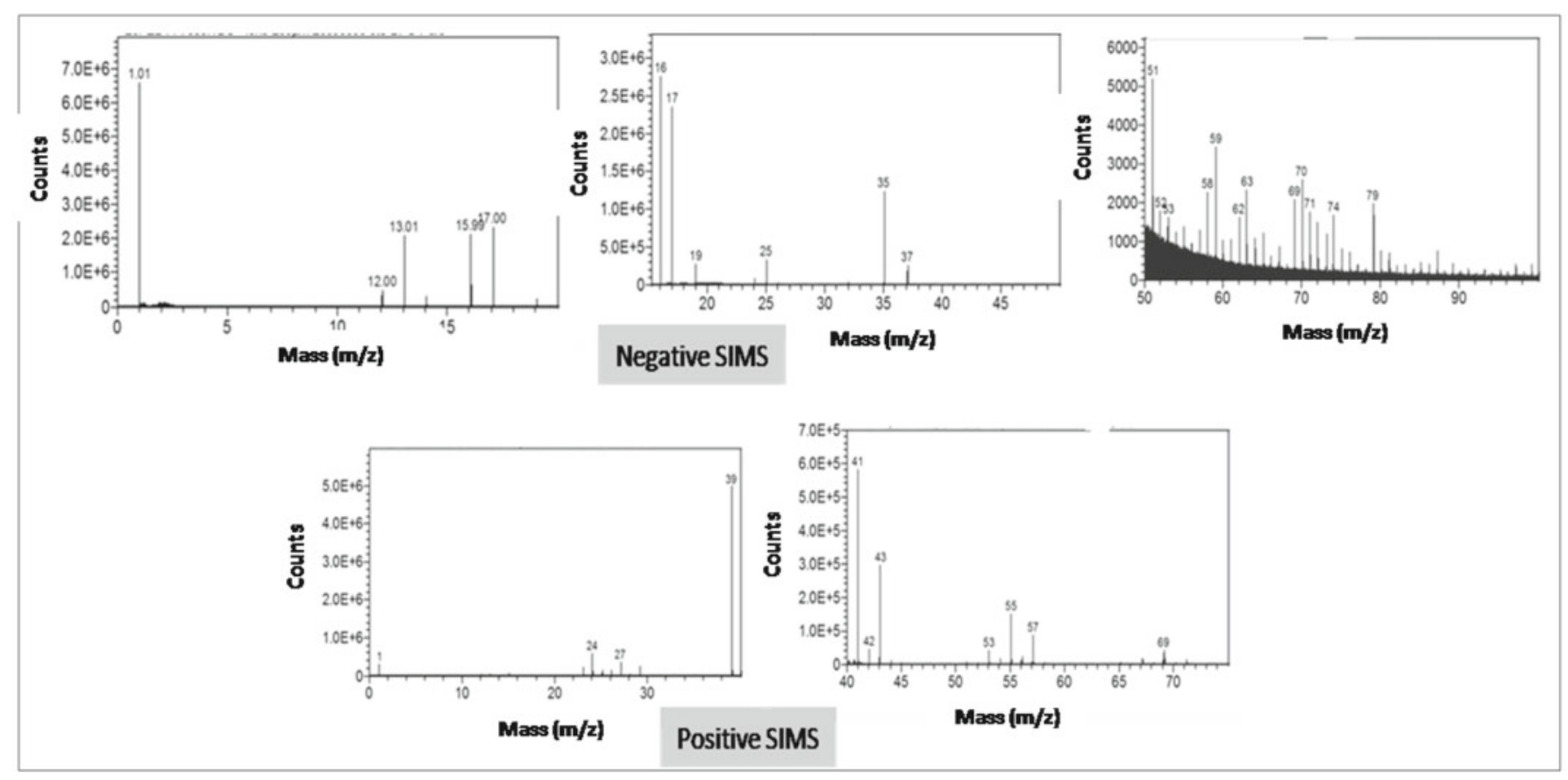

Figure 7. Mass spectroscopy of BPS
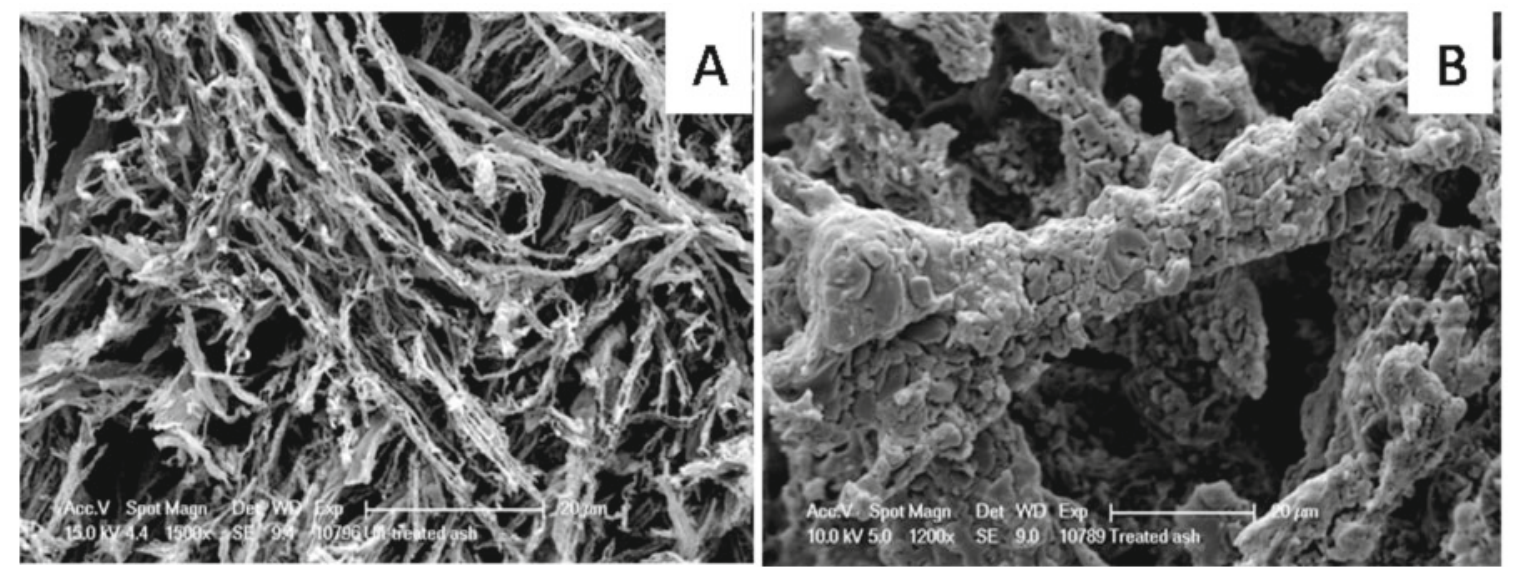

Figure 8. SEM of residual mass of control (A) and BPS treated (B) fabric

sition and enhances the insulated char formation. On the other hand, the control fabric showed poor char structure without any closed cells, but with prominent channels through which the volatile gas or the decomposed polymer can escape. The same phenomenon has been reported in an earlier literature ${ }^{29}$.

\section{Mechanism of imparting flame retardant property}

Cotton is pure cellulosic in nature, has a low LOI value of 18 and as such, does not show any resistance to flame. Even, after mordanting with alum and tannic acid, the flame retardancy of cotton textiles does not improve as observed from Table 1 and the TGA curves (Fig. 2). This implies that the molecules present in alum and tannic acid do not have any role in imparting flame 
retardant finishing to cellulose. In our experiment, it was observed that the uptake/exhaustion of the BPS by cellulosic textiles was very low when the samples were treated without any mordanting agent. However, prior mordanting of the cotton textile followed by application of the BPS in alkaline condition, ensures a good add-on (with 2-4.5\% uptake) of the BPS on the textile. This implies that cotton is showing flame retardancy mainly because of the BPS, and partially due to the interaction of the BPS with the mordant. The effect of flame retardancy imparted by the BPS may be attributed to the presence of phosphate, chloride and other mineral salts present in the sap. The phosphate present in the BPS treated sample is mainly in the form of calcium phosphate and sodium phosphate. Similarly, the other metals present in the cotton textile is in the form of chloride, such as magnesium chloride, calcium chloride, potassium chloride, etc. The presence of these molecules, i.e., chloride and phosphate was also observed with the mass spectroscopy, and as the peaks of the elements in the EDX analysis. In this regard, it is worth mentioning that a recent study has reported a realisation of $10.5 \mathrm{~g}$ inorganic salts from the evaporation of $500 \mathrm{ml}$ of aqueous ash extract collected by burning the air-dried banana pseudostem. The researchers have also reported that potassium chloride, sodium chloride and metal phosphate are the major composition of that salt ${ }^{\mathbf{1 3}}$, and magnesium nitrate and potassium nitrate are the two major active components present in the BPS as confirmed by GC-MS analysis, and those can also act as fire retardant ${ }^{15}$. In the present study, the BPS has helped the cotton textile not only to be flame retardant, but also to form some sort of complex groups with the mordants that might have also aided the sample to be better flame retardant, resulting in high uptake of the BPS in the pre-mordanted fabric. From the various characterizations made in the study, it is presumed that phosphate, chloride and other mineral salts might have retarded the thermal decomposition of cellulose and contributed to the dehydration process by increasing the amount of char formation, as shown in the TGA curve. Phosphate containing molecules are already known to be flame retardant ${ }^{21}$. Metal chlorides have also been reported as fire retardants for the cotton cellulose ${ }^{\mathbf{2 6}}$. Besides, the presence of water molecules in BPS as shown in FTIR curve C (Fig. 4) might have contributed in preventing the rise in temperature of the sample by absorbing the heat of evaporation $(540 \mathrm{cal} /$ $\mathrm{gm})$. The presence of moisture peak has been observed in FTIR spectra and in TGA curves. Therefore, the flame retardancy observed in the banana pseudostem sap (BPS) treated cotton fabric might have possibly attributed to the combined effect of (i) phosphate compounds, (ii) metal salts, especially potassium chloride, and (iii) the bound and the unbound water molecules present in the BPS. These might have helped in more char and less flammable gas formation. Additionally, the presence of approximately $14 \%$ inorganic material and reduction of similar quantity of organic material (cellulose) might have helped the production of more char with no calorific value, while reducing the formation of flammable gases due to pyrolysis of cellulose as seen in the TGA curves. This later phenomena may be attributed due to the presence of organometallic additives in the cellulosic cotton fabric, which has increased the char formation and also reduced the tar formation ${ }^{27}$.

As far as the flame retardancy mechanism is concerned, the BPS mainly acts in the condensed phase mechanism. It might be because it contains phosphate, phosphite and other metallic constituents which are helping to influence the pyrolysis of the treated fabric by forming char at an earlier stage, as observed from the TGA curves. From the SEM pictures of the treated fabric, it was also observed that BPS provides a thick protective coating on the cellulosic cotton fabric surface. When this treated cotton fabric was exposed to heat or flame, it favours the formation of a stable and protective char that limits the exchange of oxygen and combustible volatile products, thus adding to enhance the flame retardancy of the cotton textile. This phenomenon can be verified from both the TGA and the SEM pictures of the residual mass of the BPS treated cotton fabric. Here, the BPS coating also might have acted as an intumescent that swells on heating and increases its volume, thus protecting the underlying polymeric material from heat or flame by char insulation and foaming. The coating protected the remaining polymer from thermal decomposition and enhanced the insulated char formation. On the other hand, the control fabric showed a poor char formation without any closed cells, but with prominent channels through which any volatile gas or decomposed polymer can escape.

\section{Wash durability}

The durability of the imparted flame retardant finish was determined from the measure of effectiveness of the finish after washing the sample with soap solution. It can be seen (Table 4 ) that the LOI value of the washed fabric decreased from 30 to 24 from 1: 0 BPS treated unwashed to wash samples. As a result, the washed sample burns slightly faster due to partial removal of the active BPS molecules such as metal salts, phosphate and silicates. Similar results have also been observed under the SEM (Fig. 5 (C)), where less deposition/coating is visible compared to the as-prepared sample. It might be due to the fact that BPS act as an additive flame retardant to cellulosic cotton fabric, and as such, there is no chemical reaction or bond formation between the elements of the BPS and the cellulose polymer. However, the measured LOI value of 24 for the washed BPS treated sample is still significantly higher by 1.3 times than that recorded with the control sample with LOI of 18 (Table 4). The burning rate was found to increase from $7.5 \mathrm{~mm} / \mathrm{min}$ for the unwashed to $20 \mathrm{~mm} / \mathrm{min}$ for the wash fabric, i.e., by about 2.5 times.

However the present application was found to have no significant adverse effect on either the tensile or the tear strength. In most cases of application of conventional

Table 4. Flammability parameters of treated and washed fabric

\begin{tabular}{|c|c|c|c|}
\hline \multirow{3}{*}{$\begin{array}{l}\text { Flammability } \\
\text { parameters }\end{array}$} & \multicolumn{3}{|c|}{ Fabric parameters } \\
\hline & \multirow[b]{2}{*}{$\begin{array}{l}\text { Control } \\
\text { sample }\end{array}$} & \multicolumn{2}{|c|}{ Sap treated (1: 0) sample } \\
\hline & & $\begin{array}{c}\text { After } \\
\text { washing }\end{array}$ & $\begin{array}{l}\text { Before } \\
\text { washing }\end{array}$ \\
\hline LOI & 18 & 24 & 30 \\
\hline \multicolumn{4}{|c|}{ Horizontal flammability } \\
\hline $\begin{array}{l}\text { Warp way burn } \\
\text { rate }[\mathrm{mm} / \mathrm{min}]\end{array}$ & 75 & 20 & 7.5 \\
\hline
\end{tabular}


and commercial flame retardant finishes, there occured a significant loss of tensile strength, in the range of $10-30 \%$. The K/S (depth of colour) changed from 0.04 for the control to 0.80 for the 1: 2 BPS treated samples. With further increase in the BPS concentration, K/S was found to increase and L (lightness-darkness) tends to decrease.

\section{CONCLUSIONS}

The present study has demonstrated the flame retardancy effect of banana pseudostem sap (BPS) on the cellulosic cotton textile and postulated the scientific basis of the same. After application of BPS, the LOI increased from 18 to 30 in the BPS treated (1: 0) samples. Due to higher LOI, the total burning time could be increased from $60 \mathrm{~s}$ in the control sample to $900 \mathrm{~s}$ in the BPS treated sample. This will provide more safety time to a human being either to extinguish the fire or to escape from zone of fire hazards. Only banana pseudostem sap without any dilution i.e., with 1: 0 ratio was found to be the best for application in the cotton textile under alkaline condition. The flame retardancy in the BPS treated cotton fabric might be attributed to the presence of (i) phosphate compounds, (ii) metal salts, especially sodium and potassium chloride, and (iii) water molecules. Also, the presence of approximately $14 \%$ of inorganic materials in the BPS treated cellulose textile might have aided in the production of more char and nonflammable gases. The dehydration and the char formation phenomena in the BPS treated cotton fabrics have been observed in the TGA curves. The proposed application process is simple and cost-effective, as no costly chemicals are used. Further, the added advantage is that the BPS treated fabric could also be considered as a naturally dyed cotton fabric. The developed khaki colour is quite attractive and stable to sunlight exposure. This reported process can be used beneficially in colouration and in imparting flame retardant finishing of home furnishing products such as window curtain, railway curtain, hospital curtain, table lamp, and as a covering material of non-permanent structures like those used in book fair, festival, religious purposes and such on, where a large quantity of textile is used thus, posing possible threats of fire hazards. Banana pseudostem sap is abundantly available in India as well as in some other countries, and is normally considered as a waste material, though it is an eco-friendly natural product and produced from a renewable source. Therefore, the application of the BPS in cotton textile for colouration and functionalization offers an attractive proposition.

\section{LITERATURE CITED}

1. Kandola, B.K., Horrocks, A.R., Price, D. \& Coleman G.V. (2006). Flame retardant treatments of cellulose and their influence on the mechanism of cellulose pyrolysis. J. Macromol. Sci., 36(4), 721-794. DOI: 10.1080/15321799608014859.

2. Charuchinda, S., Srikulkit, K. \& Mowattana, T. (2005). Coapplication of sodium polyphosphateand chitosan to improve flame retardancy of cotton fabric. J. Sci. Res. Chula. Univ., 30 (1), 97-110. DOI: 10.1177/0734904112443658.

3. Horrocks, A.R. (2011). Flame retardant challanges for textiles and fibres. Polym. Degrad. Stabil., 96 (3), 377-392. DOI: $10.1016 /$ j.polymdegradstab.2010.03.036.
4. Kei, S.C.H. (2010). The effect of atmospheric pressure plasma on flame retardant property of cotton. Institute of Textile and Clothing, Bachelor of Arts in Fashion Technology thesis, Hong Kong Polytechnic University.

5. Katovic, D., Grgae, S.F., Vukusic, S.B. \& Katovic, A. (2012). Formaldehyde free binding systems for flame retardant finishing of cotton fabrics. Fibres Text. East. Eur. 1(90), 94-98.

6. Nguyen, T.M.D., Chang, S., Condon, B., Uchimiya, M. \& Fortier, C. (2012). Development of an environmentally friendly halogen free phosphorous nitrogen bond flame retardants for cotton fabrics. Polym. Adv. Technol. 23, 1555-1563. DOI: 10.1002/pat.3029.

7. Hady, A.A.E., Farouk, A. \& Sharaf, S. (2013). Flame retardancy and UV protection of cotton based fabrics using nano ZnO and polycarboxylic acid. Carbohydr. Polym. 92 (1), 400-406. DOI: 10.1016/j.carbpol.2012.08.085.

8. Sarvanan, D., Lakshmi, S.N.S., Raja, K.S. \& Vasahi, N.S. (2013). Biopolishing of cotton fabric with fungal cellulose and its effect on the morphology of cotton fibres, Indian. J. Fibre Text. Res. 38 (2), 156-160.

9. Joshi, M., Ali, S.W. \& Rajendran, S. (2007). Antibacterial finishing of polyester cotton blend fabric using neem: A natural bioactive agent. J. Appl. Polym. Sci.106 (2), 793-800. DOI: $10.1002 /$ app.26323.

10. Salah, S.M. (2012). Antibacterial activity and UV protective property of some Egyptian cotton fabrics treated with aquous extract of banana peel. Int. J. Cloth. Sci. 1(1), 1-6. DOI: $10.5923 /$ j.clothing.20120101.01.

11. Alongi, J., Carletto, R.A., Balsio, A.D., Cuttica, F., Carosio, F., Bosco, F. \& Malucelli, G. (2013). Intrinsic intumescent like flame retardant properties of DNA treated cotton fabrics. Carbohydr. Polym. 96(1), 296-304. DOI: 10.1016/j carb pol.2013.03.066.

12. Bosco, F., Carletto, R.A., Alongi, J., Marmo, L., Blasio, A.D. \& Malucelli, G. (2012). Thermal stability of flame resistantance of cotton fabrics treated with whey proteins. Carbohydr. Polym. 94(1), 372-377. DOI: 10.1016/j Carb pol.2012.12.075.

13. Carosio, F., Blasio, A.D., Cuttica, F., Alongi, J. \& Malucelli, G. (2014). Polyester and polyester cotton blend fabrics have been treated with caseins. Ind. Eng. Chem. Res. 53(10), 3917-3923. DOI: 10.1021/ie404089t.

14. Kolambe, B.N., Patel, K.K., Pawar, S.L., Patel, J.M. \& Prajapati, D.R. (2013). WIPO patent No. WO/2013/001478.

15. Sayed M.E., Mansour O.Y., Selim I.Z. \& Ibrahim M.M. (2001). Identification and utilisation of banana plant juice and its pulping liquors as anticorrosive materials. J. Sci. Ind. Res. 60, 738-747. DOI: org/10.1155/2013/784186.

16. Neog, S.R. \& Deka, C.D. (2013). Salt substitute from banana plant (Musa Balbiciana Colla). J. Chem. Pharm. Res. 5 (6), 155-159.

17. Petrilli, T. (2008). Technology and development programme, 0851-2348P-MTDC: 1-10.

18. White, H.R., Nam, S. \& Parika, V.D. (2012). Cone calorimeter evaluation of two flame retardant cotton fabrics. Fire Mater. 37 (1), 46-57. DOI: 10.1002/fam.2111.

19. Shen, Y.M., Kuan, F.C., Kuan, C.H., Chen, H.C., Wang, H.J., Yip, C.M. \& Chiang, L.C. ( 2013). Preparation , characterization, thermal, and flame retardant properties of green silicon containing epoxy functionalized grapheme nanosheets composites. J. Nanomat. 2013, 1-10. DOI: 10.1155/2013/747963. 20. Xing, T.L., Liu, J., Li, S.W. \& Chen, G.Q. (2012). Thermal properties of flame retardance cotton fabric grafted by dimethyl methacruloyloxyethylphosphate. Therm. Sci. 16 (5), 1472-1475. DOI: 10.2298/TSCI1205472X.

21. Mostashari, S.M. \& Mostashari, S.Z. (2009). Thermogravimetry of deposited ammonium aluminium sulphate dodecahydrate used as flame retardant for cotton fabrics. Cellul. Chem. Technol. 43 (9-10), 455-459. 
22. Karastergiou, P.S. \& Philippou, J.L. (2000). Thermogravimetric analysis of fire retardant treated particle boards. Wood Fire Saf. (pp. 388-392).

23. Cilurzo, F., Selmin, F., Minghetti, P. \& Montanari, L. (2005). The effects of bivalent inorganic salts on the mucoadhesive performance of a polymethylmethacrylate sodium salt. Int. $J$. Pharm. 301 (1-2), 62-70. DOI: 10.1016/j.ijpharm.2005.05.029. 24. Miller, A.F. \& Wilkins, H.C. (1952). Infrared spectra and characteristic frequencies of inorganic ions. Anal. Chem. 24 (8), 12530-1294. DOI: 10.1021/ac60068a007.

25. Honeycutt, W., Xing, B., Mcdowell, W.R., Pellechias, J.P. \& Zhang, T. (2007). Solid state fourier transform infrared and 31P nuclear magnetic resonance spectral features of phosphate compound. Soil Sci. 172 (7), 501-515. DOI: 10.1097/ SS.0b013e318053dba0.

26. Mostashari, S.M. \& Baie, S. (2010). Superiority of lithium bromide over lithium chloride used as flame retardants on cotton substrates. Cellul. Chem. Technol. 44 (7-8), 299-303.

27. Soares, S., Camino, G. \& Levchik, S. (1998). Effect of metal carboylates on the thermal decomposition of cellulose. Polym. Degrad. Stabil. 62 (1), 25-31. DOI: 10.1016/S01413910(97)00256-5.

28. Banerjee, S.K., Day, A. \& Ray, P.K. (1985). Fire proofing jute. Text. Res. J. 56 (5), 338-339. DOI: 10.1177/004051758605600510. 29. Levchik, S.V. \& Wikie, C.A. (2000). In A.F. Grand \& C.A. Wikie (Eds.), Fire Retard. Polymer. Mater. 171-215. Marcel Dekker Inc, NewYork. 